\title{
Alpha-Lipoic Acid for the Prevention of Diabetic Macular Edema
}

\author{
Christos Haritoglou ${ }^{a}$ Joachim Gerss ${ }^{b}$ Hans P. Hammes ${ }^{c}$ Anselm Kampik ${ }^{a}$ \\ Michael W. Ulbig ${ }^{\text {a }}$ for the RETIPON Study Group ${ }^{1}$ \\ ${ }^{a}$ Department of Ophthalmology, Ludwig Maximilian University, Munich, ${ }^{b}$ Institute of Biostatistics and \\ Clinical Research, University of Münster, Münster, and ${ }^{`} 5$ th Medical Department, University Hospital \\ Mannheim, Mannheim, Germany
}

\section{Key Words}

Diabetic macular edema - Insulin-dependent diabetes • $\alpha$-Lipoic acid · Type II diabetes mellitus

\begin{abstract}
Introduction: To evaluate the effect of $\alpha$-lipoic acid (ALA) on the occurrence of diabetic macular edema. Methods: Randomized, double-blind, placebo-controlled, multicenter, multinational study. Patients were randomized to the treatment group with $600 \mathrm{mg}$ ALA per day or the placebo group. Every 6 months stereo fundus photographs, HbA1c levels, and an ophthalmological examination were documented. The primary endpoint was the occurrence of clinically significant macular edema (CSME) within a follow-up period of 2 years. Results: We randomized 235 patients with type II diabetes mellitus into the treatment group (mean age 58.0 years) and 232 into the placebo group (mean age 57.9 years). Mean $\mathrm{HbA1}$ c level was 8.1, with no significant differences between the treatment (mean 8.2, SD \pm 1.35) and placebo groups (mean 8.1, SD \pm 1.29). HbA1c values remained constant over time. In the treatment and placebo groups, 84 and 86 patients (35.7 and $37.1 \%$ ) had insulin-dependent diabetes
\end{abstract}

mellitus (IDDM) with a median duration of diabetes of 9.3 versus 9.0 years in the placebo group. Visual acuity remained unchanged during the entire trial. Concerning the primary endpoint, the study provided a negative result, i.e. 26/235 patients in the treatment group and 30/232 patients in the placebo group developed CSME. Confirmatory intention-totreat analysis of the primary endpoint revealed no statistically significant difference between groups (log-rank test, $\mathrm{p}=0.7108, \mathrm{HR}=0.9057$ with $\mathrm{Cl}=0.5355-1.5317)$. Median follow-up was identical (2.00 years). Conclusions: A daily dosage of $600 \mathrm{mg}$ ALA does not prevent the occurrence of CSME in IDDM patients.

Copyright $\odot 2011$ S. Karger AG, Basel

\section{Introduction}

Diabetic retinopathy including macular edema is the most frequent cause of blindness in Western industrialized nations [1-3]. Prevention of visual loss depends on timely detection of diabetic retinopathy and instant-laser treatment. As a timely and close glycemic control with near-normal HbAlc levels and blood pressure below

\section{KARGER \\ Fax +41613061234 E-Mail karger@karger.ch} www.karger.com
(C) 2011 S. Karger AG, Basel $0030-3755 / 11 / 2263-0127 \$ 38.00 / 0$

Accessible online at: www.karger.com/oph
Christos Haritoglou, MD

Department of Ophthalmology, Ludwig Maximilian University

Mathildenstrasse 8

DE-80336 Munich (Germany)

Tel. +49895160 3084,E-Mail christos.haritoglou@med.uni-muenchen.de 
130/80 mm Hg cannot always be achieved, medical therapy to prevent the occurrence and progression of sightthreatening complications remains a challenge.

Retinal damage induced by diabetic macular edema is due to vascular leakage and nonperfusion [4]. Sustained hyperglycemia affects several vasoactive factors, notably vascular endothelial growth factor, protein kinase $\mathrm{C}$ and angiotensin II, all of which are interrelated and may influence the development of structural and functional changes in diabetic retinopathy [4-9]. The upregulation of vascular endothelial growth factor is associated with a breakdown of the blood-retinal barrier and increased vascular permeability resulting in retinal edema $[9,10]$. High glucose levels in endothelial cells are associated with a mitochondrial overproduction of reactive oxygen species, which inactivate glyceraldehyde-3-phosphate dehydrogenase [11]. This process plays a role in the pathogenesis of endothelial damage [12]. Therefore, antioxidants appear to be a therapeutic approach. $\alpha$-Lipoic acid (ALA) differs in several aspects from other antioxidants [13-15] as it distributes to mitochondria, has a very low redox potential, recycles other cellular antioxidant redox pairs (such as ascorbate) and is regenerated by hyperglycemia and nonessential fatty acid-induced nicotinamide adenine dinucleotide phosphate (via pyruvate dehydrogenase), linking the antioxidant activity to the degree of increased metabolic flux [16].

The potential of ALA in preventing microvascular damage has been demonstrated in animals [17]. ALA has been used for years in the long-term treatment of chronic sensorial disorders in diabetic polyneuropathy at a dosage of $600 \mathrm{mg} /$ day. We raised the hypothesis that a beneficial effect may also be seen in diabetic retinopathy and in the prevention of clinically significant macular edema (CSME) [18-24].

\section{Methods}

Study Design

The RETIPON Study is a phase III, randomized, multicenter, multinational, double-blind, placebo-controlled, comparative trial to evaluate a potential effect of ALA in prolonging the time interval between the diagnosis of mild to moderate diabetic retinopathy at enrolment and the development of CSME in high-risk insulin-dependent diabetes mellitus (IDDM) patients.

The study was approved by the local ethics committee.

Inclusion and Exclusion Criteria (table 1)

We included outpatients, male or female, with diagnosed adult-onset IDDM, aged 45-68 years, showing mild to moderate nonproliferative diabetic retinopathy (NPDR) according to the
Table 1. Exclusion criteria

Ophthalmic exclusion criteria

- Severe nonproliferative or proliferative diabetic retinopathy

- Macular edema

- Eye diseases interfering with the examinations of the fundus such as preretinal hemorrhage, cataract, vitreous hemorrhage

- Amblyopia

- Best corrected visual acuity $\leq 0.5$

- Glaucoma

- Patients with cataract surgery within a period of 3 months

- Other relevant retinal diseases

- Unauthorized interventional therapy of diabetic retinopathy (e.g. laser, kryocoagulation, vitrectomy)

General exclusion criteria

- Chronic administration of ALA or for more than 5 successive days during the last 12 months

- Known intolerance/hypersensitivity to ALA

- Type I diabetes mellitus

- Poor metabolic control with HbA1c >10.5\%/dl

- Late sequelae of diabetes with organic manifestation (e.g. dialysis in cases of renal insufficiency, history of kidney transplantation, creatinine $>1.6 \mathrm{mg} / \mathrm{dl}$ )

- Poorly controlled arterial hypertension (systolic blood pressure $>160 \mathrm{~mm} \mathrm{Hg}$ and/or diastolic blood pressure $>95 \mathrm{~mm} \mathrm{Hg}$ )

- Severe disturbances in lipid metabolism (triglycerides $>500$ $\mathrm{mg} / \mathrm{dl}$ or total cholesterol $>320 \mathrm{mg} / \mathrm{dl}$ )

- Unauthorized concomitant medications, defined as any medicine with a potential interaction with ALA or with the effect of ALA, were excluded as concomitant medications. These included aldose reductase inhibitors, substances promoting blood flow, anticoagulants apart from acetylsalicylic acid $\leq 500 \mathrm{mg} /$ day and short-term treatment of diseases with the normal dose of acetylsalicylic acid, chronically and systemically administered corticosteroids, hormonal contraceptives

- Malignancies or life-threatening diseases

- Drug or alcohol abuse

- Blood donation or blood loss greater than $500 \mathrm{ml}$ within the last 3 months

- Pregnancy or breast-feeding

- Participation in a clinical trial within the last 30 days

classification of the ETDRS protocol [25] in at least one eye and presenting with microalbuminuria $>30 \mathrm{mg} / \mathrm{l}$ as diagnosed with a urine dipstick microalbumin test (Micro-Bumintest ${ }^{\circledR}$, Bayer ${ }^{\circledR}$, Leverkusen, Germany). These patients are known to bear a high risk for microvascular complications such as CSME. Patients were insulin dependent or non-insulin dependent. Written informed consent had to be given.

Treatment Modalities and Randomization

The 600-mg dosage of ALA was established for treatment of peripheral polyneuropathy. The chemical name of the investigational drug is 1,2-dithiolane-3-valeric acid. The trial medication 
was prepared in compliance with Good Manufacturing Practice (GMP), packed and supplied by Bausch \& Lomb, Berlin, Germany).

The trial medication had been granted marketing authorization and was newly packed in blister packs and relabeled as 600 mg tablets. The placebo and the drug tablets were similarly packed and labeled, and had an identical appearance and taste.

The number of tablets dispensed at the visits was recorded and subjects were instructed to return any unused medication at the next visit. All returned medications were counted to determine the actual number of tablets taken. Noncompliance was defined as an intake of less than $80 \%$ of the medication between visits.

Eligible patients accomplished a 4 -week compliance test phase starting with visit 1 . In case of at least $80 \%$ compliance, they were randomized at visit 2 (day 0 ) to receive either ALA 600-mg tablets once daily or placebo for a 24 -month period. After inclusion, patients were followed at 6-month intervals.

A block design was used for randomization. Random numbers were allocated in ascending order corresponding to the order in which subjects were included after the examination on visit 2 . Each patient was allocated to either active treatment or placebo using a stratified randomization within the investigation center as well as the following strata: $1=\mathrm{HbAlc}<9 \%$, IDDM; $2=\mathrm{HbAlc}$ $<9 \%$, non-IDDM (NIDDM); $3=$ HbAlc $\geq 9 \%$, IDDM, and $4=$ HbAlc $\geq 9 \%$, NIDDM.

Date and time of randomization (i.e. the time point at which the current random number was allocated) were recorded for each subject. The balance of randomization was approved.

The randomization code for the trial investigational medicinal product was provided to the investigator in separate sealed envelopes (emergency envelope) labeled with trial and randomization code numbers. The breaking of the treatment code was strictly forbidden except in the event of a medical emergency. The sponsor had to be immediately notified and the reason for breaking the code documented in the subject's medical records and on the case report form. The investigator assessed the relationship of the adverse event to the trial investigational medicinal product before the treatment code was broken.

\section{Medical Review and Physical Examination}

Blood samples for laboratory tests obtained at visit 1, and 3-6 included RBC, WBC, platelet count, hemoglobin, hematocrit, GOT, GPT, $\gamma$-GT, creatinine, urea, uric acid, HbAlc, fasting blood glucose, total cholesterol, triglycerides. Morning urine was checked by a dipstick test for glucose, total protein, and bilirubin at visit 1 on-site. Laboratory tests were performed in a single central laboratory for all centers (MDS Pharma Services, Hamburg, Germany). Clinically relevant findings were documented in the case report form as adverse events and treated accordingly. All clinically relevant abnormal laboratory results were to be followed up until they returned to normal (i.e. to baseline), stabilized or could be explained otherwise.

At the initial visit, the patient's body weight, height, blood pressure and concomitant medication were recorded. In addition, a complete medical examination was performed. Systolic and diastolic blood pressure and pulse rate were measured at visit 1 and visits 3-6 after a 10-min rest in the supine position and recorded in the case report form. All blood pressure measurements were made on both arms using a sphygmomanometer with an appro- priate cuff size for the individual subject and the mean value was calculated.

\section{Ophthalmic Examination and Method of Macular Edema \\ Detection}

At each visit, i.e. every 6 months, patients underwent bilateral eye examination including best corrected visual acuity using the Early Treatment Diabetic Retinopathy Study (ETDRS) charts, slit lamp examination, intraocular pressure, and stereoscopic biomicroscopy. Seven-field stereo fundus photographs (in color $30^{\circ}$ ) according to the criteria of the ETDRS protocol [25] were taken. The quality of the photographs was assessed immediately upon receipt by the senior author (M.W.U.). In cases of insufficient quality, the respective center was asked to submit a new set of photographs. Fluorescein angiography at the beginning and end of the study was optional and evaluated according to the ETDRS protocol [26]. Adverse events whether or not considered to be caused by the study medication had to be reported.

Macular edema was diagnosed on stereoscopic fundus photographs according to the ETDRS protocol [26]. The fundus photographs were always evaluated by two masked examiners at the RETIPON Reading Center in Munich, Germany, under the guidance of the senior author (M.W.U.). Both graders had to concur on the final assessment and potential differences in the grading were discussed by the graders. Graders were all certified to ETDRS standards. The same applied for all participating photographers in the study centers. Optical coherence tomography (OCT) scans were neither adequate nor possible. Most participating centers had no OCT device, and OCT scans are more useful to measure changes in preexisting macular thickening.

\section{Primary and Secondary Endpoints}

Detection of CSME in at least one eye was defined as the primary endpoint. Both eyes were graded at each visit. Following detection of CSME in the central reading center, its occurrence was immediately reported and the patient was appropriately treated by laser and excluded from further follow-up.

Secondary objectives were the development of neovascularization elsewhere or at the disk, changes in severity of diabetic retinopathy according to the ETDRS severity scale [25], the course of best corrected visual acuity, and contrast sensitivity as well as cataract formation measured by the Lens Opacity Classification System II.

\section{Statistical Analysis}

The statistical evaluation was based on a group sequential design with one interim and a final analysis. Using the O'BrienFleming approach and the Lan-De Mets $\alpha$-spending function methodology in the primary analysis, the single significance levels for an overall level of $\alpha=0.05$ are $\alpha_{1}=0.0054$ for the interim analysis and $\alpha_{2}=0.0492$ for the final analysis. This report presents the results of the final analysis.

As in the O'Brien-Fleming approach, the final analysis keeps close to the overall significance level and has approximately the same power as a fixed-sample design, a fixed-sample approach was applied for sample size and power calculation. The effect size estimation was based on expert ratings from experienced ophthalmologists. It was assumed that we had a $62 \%$ event-free survival in the placebo group after 2 years and a $75 \%$ event-free survival in the treatment group. Given these assumptions and 
Table 2. Summary of baseline characteristics

\begin{tabular}{|c|c|c|c|c|}
\hline & ALA & Placebo & Total & $\mathrm{p}$ value \\
\hline Randomized, n & 235 & 232 & 467 & \\
\hline \multicolumn{5}{|l|}{ Demographic characteristics } \\
\hline \multicolumn{5}{|l|}{ Sex } \\
\hline Male, $\mathrm{n}$ & $101(43.0 \%)$ & $94(40.5 \%)$ & $195(41.8 \%)$ & \multirow{2}{*}{0.5897} \\
\hline Female, $\mathrm{n}$ & $134(57.0 \%)$ & $138(59.5 \%)$ & $272(58.2 \%)$ & \\
\hline \multicolumn{5}{|l|}{ Age, years } \\
\hline Mean $\pm S D$ & $58.0 \pm 6.11$ & $57.9 \pm 6.30$ & $57.9 \pm 6.20$ & \multirow{2}{*}{0.8556} \\
\hline Range & $44-68$ & $45-69$ & $44-69$ & \\
\hline \multicolumn{5}{|l|}{ Baseline characteristics } \\
\hline \multicolumn{5}{|l|}{ Degree of retinopathy } \\
\hline Microaneurysms only, $\mathrm{n}$ & $17(7.2 \%)$ & $14(6.0 \%)$ & $31(6.6 \%)$ & \multirow{5}{*}{0.4342} \\
\hline Mild NPDR, $\mathrm{n}$ & $188(80.0 \%)$ & $196(84.5 \%)$ & $384(82.2 \%)$ & \\
\hline Moderate NPDR, $\mathrm{n}$ & $28(11.9 \%)$ & $22(9.5 \%)$ & $50(10.7 \%)$ & \\
\hline Moderately severe NPDR, $\mathrm{n}$ & $1(0.4 \%)$ & 0 & $1(0.2 \%)$ & \\
\hline Severe NPDR, $\mathrm{n}$ & $1(0.4 \%)$ & 0 & $1(0.2 \%)$ & \\
\hline \multicolumn{5}{|l|}{ Type of treatment for DM } \\
\hline IDDM, $\mathrm{n}$ & $84(35.7 \%)$ & $86(37.1 \%)$ & $170(36.4 \%)$ & \multirow[b]{2}{*}{0.7662} \\
\hline NIDDM, $\mathrm{n}$ & $151(64.3 \%)$ & $146(62.9 \%)$ & $297(63.6 \%)$ & \\
\hline Stratum 1, HbA1c < $9 \%$, IDDM, n & $53(22.6 \%)$ & $56(24.1 \%)$ & $109(23.3 \%)$ & \multirow{4}{*}{0.9821} \\
\hline Stratum $2, \mathrm{HbA} 1 \mathrm{c}<9 \%$, NIDDM, n & $110(46.8 \%)$ & $107(46.1 \%)$ & $217(46.5 \%)$ & \\
\hline Stratum $3, \mathrm{HbA} 1 \mathrm{c} \geq 9 \%$, IDDM, $\mathrm{n}$ & $31(13.2 \%)$ & $30(12.9 \%)$ & $61(13.1 \%)$ & \\
\hline Stratum $4, \mathrm{HbA} 1 \mathrm{c} \geq 9 \%$, NIDDM, $\mathrm{n}$ & $41(17.4 \%)$ & $39(16.8 \%)$ & $80(17.1 \%)$ & \\
\hline Median duration of DM, years & 9.3 & 9.0 & 9.1 & 0.7348 \\
\hline Mean HbA1c (SD, range), \% & $8.2(1.35,3.8-10.5)$ & $8.1(1.29,5.3-10.5)$ & $8.1(1.32,3.8-10.5)$ & 0.4087 \\
\hline \multicolumn{5}{|l|}{ Study discontinuation } \\
\hline Total (at least one of the below reasons), $\mathrm{n}$ & $39(16.6 \%)$ & $29(12.5 \%)$ & $68(14.6 \%)$ & 0.2096 \\
\hline \multicolumn{5}{|l|}{ HbAlc $>10.5 \%$ at two consecutive regular } \\
\hline follow-up visits, $\mathrm{n}$ & $6(2.6 \%)$ & $6(2.6 \%)$ & $12(2.6 \%)$ & \\
\hline Inability to comply with the study medication, $\mathrm{n}$ & $1(0.4 \%)$ & 0 & $1(0.2 \%)$ & \\
\hline \multicolumn{5}{|l|}{ Inability to comply with the visit schedule } \\
\hline and/or lost of follow-up, $\mathrm{n}$ & $7(3.0 \%)$ & $8(3.4 \%)$ & $15(3.2 \%)$ & \\
\hline Malignant or other life-threatening diseases, $\mathrm{n}$ & $2(0.9 \%)$ & $2(0.9 \%)$ & $4(0.9 \%)$ & \\
\hline Necessity of not permitted concomitant medication, $\mathrm{n}$ & 0 & $1(0.4 \%)$ & $1(0.2 \%)$ & \\
\hline Unacceptable adverse events, $\mathrm{n}$ & $4(1.7 \%)$ & $2(0.9 \%)$ & $6(1.3 \%)$ & \\
\hline Withdrawal of consent, $\mathrm{n}$ & $19(8.1 \%)$ & $10(4.3 \%)$ & $29(6.2 \%)$ & \\
\hline
\end{tabular}

accounting for a $20 \%$ rate of nonevaluable patients, a required sample size of $n=260$ recruited patients per group was calculated, providing $80 \%$ power of significantly detecting treatment differences in the primary analysis. Finally, slightly fewer patients have actually been recruited. Recalculation of the power, however, showed that it still was acceptable, amounting to $75 \%$.

The primary endpoint was evaluated by a two-sided log-rank test, comparing the two treatment groups in an intention-to-treat approach (ITT). This particular hypothesis test provides confirmatory statistical evidence and constitutes the primary study result. Further supplementary analyses of the primary endpoint were performed, including Kaplan-Meier plots, a corresponding per-protocol analysis, and confidence interval (CI) estimation of the hazards ratio (HR) between the two treatment groups. Pro- portional hazard assumptions were verified using the GrambschThernau residual-based test. Secondary endpoints were evaluated, comparing means and proportions of the parameters given above between treatment groups with Student's t test and the $\chi^{2}$ test, respectively. Bonferroni adjustment was applied to prevent type I error enhancement due to multiplicity.

Beyond analyses of primary and secondary endpoints, exploratory analyses were performed. The homogeneity of the treatment groups was checked with regard to demographic and relevant pretreatment data. Further exploratory analyses comprised evaluation of safety data, subgroup analyses, and multivariate analyses of the time to CSME development.

Statistical analyses were performed using SAS software (Version 9.1.3 for Windows, SAS Institute Inc., Cary, N.C., USA). In 
general, descriptive analyses were performed, describing quantitative variables by number of values, number of missing values, mean, standard deviation (SD), minimum, median and maximum (or median and interquartile range if appropriate). Qualitative variables were described by absolute and relative frequencies of incidence or absolute and relative frequencies of variable categories. Moreover, inductive statistical analyses were performed, applying appropriate significance tests and calculating CIs. Missing values were not replaced.

Withdrawal

All subjects were free to withdraw from this trial at any time, for any reason, specified or unspecified and without impact on their future treatment. Reasons for withdrawal are summarized in table 1.

\section{Results}

Baseline Characteristics (table 2) and Main Efficacy Results

All outcome assessments were performed by masked examiners. Of all 467 patients, 235 were randomized into the treatment group and 232 into the placebo group. In the treatment group, 101 patients $(43.0 \%)$ were male and 134 female (57.0\%), versus 94 (40.5\%) and 138 (59.5\%) in the placebo group. Mean age was 58.0 years in the treatment group and 57.9 years in the placebo group. Best corrected visual acuity over all patients measured with ETDRS letters (both eyes) was 108.9 in the treatment group and 106.9 in the placebo group at visit 1 ( $\mathrm{p}=$ 0.0991 ) and remained unchanged until the final visit (107.9 vs. $104.6, \mathrm{p}=0.1464$ ).

Mean HbA1c level was 8.1 ( \pm 1.32 SD), with no significant differences seen following randomization at study entry when comparing the treatment group and placebo group. HbA1c values remained constant over time in all randomization strata. In the treatment and placebo groups, $84(35.7 \%)$ versus $86(37.1 \%)$ patients had IDDM and median duration of diabetes was 9.3 versus 9.0 years, respectively. For rates and reasons for study discontinuation, see table 2 .

At baseline, the degree of retinopathy did not significantly differ between treatment groups $(p=0.4342)$. Subsequently, the degree of retinopathy deteriorated in the placebo group with borderline significance $(\mathrm{p}=$ 0.0708) whereas it remained constant over time in the treatment group. On visit 3, significant differences in the degree of retinopathy emerged between the two groups ( $\mathrm{p}=0.0311$ ). On visits 4,5 and 6 , however, the degree of retinopathy did not show any differences between groups anymore. A more detailed description of the par- ticipants, randomization and reasons of withdrawal is shown in figure 1 .

\section{Comorbidity and Need for Medication Emerging \\ during Therapy (table 3)}

Apart from IDDM, the most common concomitant conditions were hypertension (62.5\%), coronary artery disease (8.6\%), ischemic cardiomyopathy (7.5\%), and dyslipidemia (7.1\%). Other conditions were documented in less than $6 \%$ of the ITT population. In total, 463 patients treated with an ITT approach (99.1\%) were taking a concomitant medication during the trial. Most prevalent concomitant medications, except those used for the treatment of diabetes, were enalapril maleate $(27.4 \%)$, indapamide (19.3\%), and acetylsalicylic acid (12.2\%).

\section{Primary Endpoint}

Concerning the primary endpoint, i.e. the cumulative CSME probability, the study provided a negative result: within the total observational period, 26/235 patients of the treatment group and 30/232 patients of the placebo group developed CSME. Confirmatory ITT analysis of the primary endpoint revealed no statistically significant difference between the two groups (logrank test, $\mathrm{p}=0.7108, \mathrm{HR}=0.9057$ with $\mathrm{CI}=0.5355-$ 1.5317). Median follow-up was identical in the two groups (2.00 years).

Univariate Predictors of CSME Development (table 4)

Looking at all randomized patients $(\mathrm{n}=467), 411$ patients did not develop CSME during the follow-up, while CSME was observed in 56 patients. Gender, HbA1c, body weight, body mass index, arterial hypertension, duration of diabetes, age and degree of retinopathy were no significant predictors of CSME development. Diabetes treatment (IDDM vs. NIDDM) turned out to be the only baseline covariate with a significant predictive capacity for CSME development $(\mathrm{HR}=2.025, \mathrm{CI}=1.199-3.421$, $\mathrm{p}=0.0083)$.

\section{Multivariate Analysis of CSME Development}

The time to CSME development was modeled in a multivariate approach using the baseline covariates gender, diabetes treatment, HbA1c, body weight, body mass index, arterial hypertension, duration of diabetes, age, degree of retinopathy and treatment with ALA versus placebo. Except for diabetes treatment, none of the covariates proved to significantly influence CSME development. In the full model including all above covariates, the HR of IDDM versus NIDDM was 2.691 (CI = 1.469-4.929, 
Fig. 1. Consort flow chart of the RETIPON Study. PP = Per protocol.

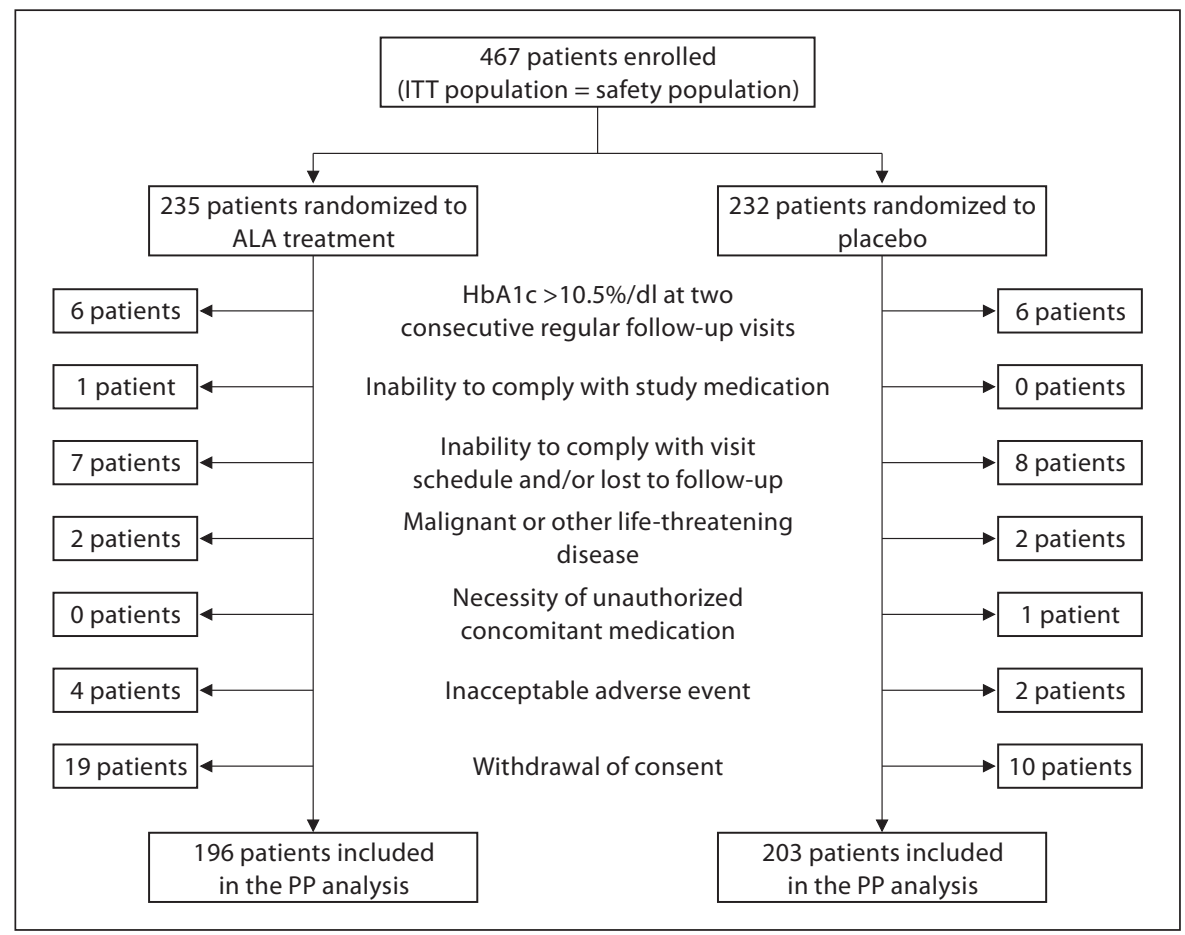

Table 3. List of cardiovascular risk factors, concomitant diseases and medications

ALA $(n=235) \quad$ Placebo $(n=232)$

Risk factors for cardiovascular disease

Baseline characteristics: blood pressure category high, $\mathrm{n}$

Medical history: hypertension, $\mathrm{n}$

Baseline characteristics: current smoker, $\mathrm{n}$

Disorder of lipid metabolism, $n$

Baseline characteristics: weight $\geq 80 \mathrm{~kg}, \mathrm{n}$

Most frequent findings of medical history

Metabolism and nutrition disorders, $\mathrm{n}$

Nervous system disorders, $\mathrm{n}$

Cardiac disorders, $\mathrm{n}$

Vascular disorders, $\mathrm{n}$

$\begin{array}{rr}208(88.5 \%) & 196(84.5 \%) \\ 146(62.1 \%) & 146(62.9 \%) \\ 29(12.3 \%) & 33(14.2 \%) \\ 168(71.5 \%) & 172(74.1 \%) \\ 115(48.9 \%) & 119(51.3 \%)\end{array}$

Eye disorders, $\mathrm{n}$

Most prevalent concomitant medications

Agents acting on the renin-angiotensin system, $\mathrm{n}$

Antithrombotic agents, $\mathrm{n}$

$\beta$-Blocking agents, $n$

Calcium channel blockers, $\mathrm{n}$

Cardiac therapy, $\mathrm{n}$

$115(48.9 \%)$

$119(51.3 \%)$

Diuretics, $\mathrm{n}$

$235(100.0 \%)$

$16(6.8 \%)$

$232(100.0 \%)$

$59(25.1 \%)$

$19(8.2 \%)$

$150(63.8 \%)$

$65(28.0 \%)$

$40(17.0 \%)$

$149(64.2 \%)$

$40(17.2 \%)$

Drugs used in diabetes, $\mathrm{n}$

Serum lipid-reducing agents, $n$

$\begin{array}{rr}131(55.7 \%) & 136(58.6 \%) \\ 30(12.8 \%) & 35(15.1 \%) \\ 43(18.3 \%) & 60(25.9 \%) \\ 56(23.8 \%) & 48(20.7 \%) \\ 54(23.0 \%) & 59(25.4 \%) \\ 53(22.6 \%) & 65(28.0 \%) \\ 234(99.6 \%) & 223(96.1 \%) \\ 32(13.6 \%) & 36(15.5 \%)\end{array}$

Concomitant medication such as acetylsalicylic acid (up to $500 \mathrm{mg} /$ day), antihypertensives and diuretics were permitted as long as such treatments had been applied for at least 3 months, were to be continued for the duration of the clinical trial, and the patient met the inclusion criteria. 
Fig. 2. Confirmatory ITT analyses of primary endpoint. The cumulative probability of developing CSME did not significantly differ between the treatment and the placebo group (log-rank test, $\mathrm{p}=$ 0.7108 , HR $=0.9057$ with $\mathrm{CI}=0.5355-$ 1.5317). During the study period, $26 / 235$ patients in the treatment group and 30/232 patients in the placebo group developed CSME.

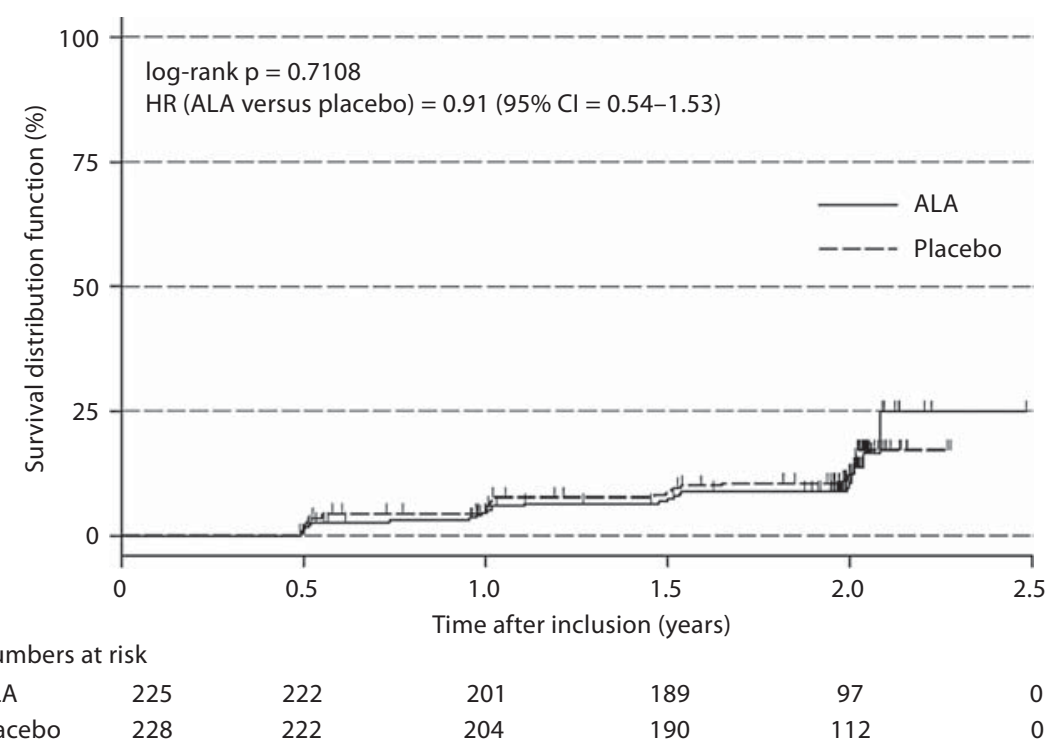

Table 4. Univariate predictors of CSME development

\begin{tabular}{|c|c|c|c|}
\hline Potential predictors & Univariate HR & $\mathrm{CI}$ & $\mathrm{p}$ value \\
\hline Males versus females & 1.288 & $0.761-2.178$ & 0.3461 \\
\hline $\mathrm{HbA} 1 \mathrm{c} \geq 9 \%$ versus $<9 \%$ & 1.045 & $0.591-1.848$ & 0.8802 \\
\hline Body weight $\geq 80 \mathrm{~kg}$ versus $<80 \mathrm{~kg}$ & 0.865 & $0.511-1.462$ & 0.5870 \\
\hline Body mass index $\geq 30$ versus $<30$ & 0.673 & $0.377-1.203$ & 0.1816 \\
\hline \multicolumn{4}{|l|}{ Systolic BP $\geq 140 \mathrm{~mm} \mathrm{Hg}$ or diastolic $\mathrm{BP} \geq 90 \mathrm{~mm} \mathrm{Hg}$ versus } \\
\hline systolic $\mathrm{BP}<140 \mathrm{~mm} \mathrm{Hg}$ and diastolic $\mathrm{BP}<90 \mathrm{~mm} \mathrm{Hg}$ & 0.965 & $0.564-1.651$ & 0.8974 \\
\hline Annual increase in the duration of diabetes & 0.995 & $0.957-1.035$ & 0.8076 \\
\hline Annual increase in age & 1.008 & $0.965-1.052$ & 0.7199 \\
\hline Mild diabetic retinopathy versus microaneurysms only & 1.182 & $0.367-3.811$ & 0.7791 \\
\hline \multicolumn{4}{|l|}{ At least moderate diabetic retinopathy versus } \\
\hline microaneurysms only & 2.172 & $0.598-7.892$ & 0.2389 \\
\hline IDDM versus NIDDM & 2.025 & $1.199-3.421$ & 0.0083 \\
\hline
\end{tabular}

$\mathrm{p}=0.0013)$. IDDM increases the risk of developing CSME by a factor of 2.691 compared to NIDDM. The only relevant covariates, diabetes treatment and HbAlc (i.e. the covariates determining the randomization strata), and (randomized) treatment with ALA versus placebo were included in a reduced model. The reduced model allows for estimation of the adjusted treatment effect that results if the possible confounders, diabetes treatment and $\mathrm{HbA1c}$, are kept constant. The adjusted HR of ALA treat- ment versus placebo amounts to 0.911 ( $\mathrm{CI}=0.539-1.541$, $\mathrm{p}=0.7276)$, indicating that active treatment does not significantly influence the time to CSME development. In further model-based analyses, it was investigated whether ALA treatment possibly shows interaction effects with baseline covariates. Interaction tests did not yield any positive results, indicating that the treatment effect was independent of baseline covariates, i.e. there was a null effect. 
Table 5. Subgroup analysis of time to CSME development

\begin{tabular}{|c|c|c|c|c|c|}
\hline & \multicolumn{2}{|c|}{ Patients } & \multirow[t]{2}{*}{ HR } & \multirow[t]{2}{*}{$95 \% \mathrm{CI}$} & \multirow{2}{*}{$\begin{array}{l}\mathrm{p} \\
\text { value }\end{array}$} \\
\hline & ALA & placebo & & & \\
\hline Stratum 1 & 53 & 56 & 1.3522 & $0.5842-3.1301$ & 0.4811 \\
\hline Stratum 2 & 110 & 107 & 0.9570 & $0.3679-2.4893$ & 0.9282 \\
\hline Stratum 3 & 31 & 30 & 0.7389 & $0.1653-3.3031$ & 0.6921 \\
\hline Stratum 4 & 41 & 39 & 0.4227 & $0.1092-1.6355$ & 0.2122 \\
\hline Male sex & 101 & 94 & 1.3272 & $0.6096-2.8898$ & 0.4758 \\
\hline Female sex & 134 & 138 & 0.6395 & $0.3040-1.3451$ & 0.2386 \\
\hline Body weight $<80 \mathrm{~kg}$ & 120 & 113 & 0.5748 & $0.2735-1.2082$ & 0.1440 \\
\hline Body weight $\geq 80 \mathrm{~kg}$ & 115 & 119 & 1.5204 & $0.6976-3.3139$ & 0.2919 \\
\hline $\mathrm{BMI}<30$ & 151 & 144 & 0.9419 & $0.5062-1.7527$ & 0.8501 \\
\hline $\mathrm{BMI} \geq 30$ & 84 & 88 & 0.8286 & $0.3084-2.2268$ & 0.7094 \\
\hline \multicolumn{6}{|l|}{ Systolic BP $<140 \mathrm{~mm} \mathrm{Hg}$ and } \\
\hline \multicolumn{6}{|l|}{ Systolic BP $\geq 140 \mathrm{~mm} \mathrm{Hg}$ or } \\
\hline diastolic $\mathrm{BP} \geq 90 \mathrm{~mm} \mathrm{Hg}$ & 135 & 148 & 0.9988 & $0.5091-1.9594$ & 0.9972 \\
\hline \multicolumn{6}{|l|}{ Baseline degree of retinopathy } \\
\hline Microaneurysms only & 17 & 14 & 1.7096 & $0.1550-18.8565$ & 0.6615 \\
\hline Mild NPDR & 188 & 196 & 0.7167 & $0.3888-1.3212$ & 0.2858 \\
\hline Moderate, moderately severe or severe NPDR & 30 & 22 & 1.5270 & $0.3816-6.1105$ & 0.5496 \\
\hline
\end{tabular}

Subgroups are determined by randomization strata (i.e., diabetes treatment and HbAlc), gender, body weight, body mass index, and hypertension. The univariate HR of ALA treatment versus placebo is estimated in each subgroup, supplemented by the $95 \% \mathrm{CI}$ and a Wald $\chi^{2}$ significance test.

\section{Subgroup Analyses (table 5)}

Exploratory post-hoc analyses were performed in order to investigate whether ALA treatment might have a positive impact on the time to CSME development in certain subgroups of patients. In none of the subgroups did a significant treatment effect emerge. Moreover, no systematic pattern became apparent that might possibly have indicated a slight trend towards a beneficial treatment effect, e.g. in 'high-risk' subgroups of patients.

\section{Safety Results}

During the trial, 109 (46\%) subjects of the ALA group and $112(48 \%)$ subjects of the placebo group reported TEAEs. Most frequently occurring events were infections, metabolism and nutrition disorders, vascular disorders, cardiac disorders and nervous system disorders.

Comparing the ALA and the placebo group, TESAEs were reported by $9 \%$ versus $10 \%$ of subjects. TEAEs in 10 versus 4 subjects were considered to be related to the trial treatment; 11 subjects in both groups reported events of severe intensity, 4 versus 2 terminated the trial prematurely due to TEAEs, death (SAEs) occurred in 2 versus 3 subjects.

\section{Conclusions}

Diabetes increases oxidative stress, which is postulated to play an important role in the development of its microvascular complications [27], such as retinopathy and macular edema, a potentially sight-threatening condition. In rats, ALA has been shown to prevent microvascular damage by normalizing pathways downstream of mitochondrial overproduction of reactive oxygen species and to preserve pericyte coverage of retinal capillaries, which may provide additional endothelial protection [16]. Others described beneficial effects on diabetic retinopathy via inhibition of accumulation of oxidatively modified DNA and nitrotyrosine [17]. Therefore, we assumed that supplementation with antioxidants such as ALA as an adjunct therapy may help to reduce the risk of visual loss in diabetic humans with NPDR.

For the present trial, we deliberately selected a highrisk population of IDDM patients with NPDR and microalbuminuria as especially the latter factor is known as a strong predictor of the development of microvascular and macrovascular complications [28] and assumed that this population may be suitable to detect potential protec- 
tive effects of our study medication. The Wisconsin data on the risk of developing macular edema [29] were based on HbAlc levels beyond $10 \%$. In our study, we aimed at an average $\mathrm{HbAlc}$ level of $8 \%$. However, we observed that ALA at the dose of $600 \mathrm{mg} /$ day provided no significant protective effect on the occurrence of CSME. Differences in the level of retinopathy as seen during the first followup visits can be neglected, as all patients included presented with very mild NPDR and low retinopathy levels. Mild changes in the retinopathy level as seen in the placebo group have no clinical relevance either. No differences between the placebo and the treatment group concerning retinopathy levels were noted later on during the trial.

A number of clinical trials, such as the ALADIN (I, II, and III), SYDNEY (I and II), and ORPIL, using ALA have been undertaken in diabetic patients to treat symptomatic diabetic peripheral neuropathy [30-36] using oral ALA supplements from 600 up to $1,800 \mathrm{mg} /$ day. ALA was administered both intravenously at doses of 600-1,200 $\mathrm{mg} /$ day for up to 3 weeks, sometimes combined with prolonged administration of additional oral medications [30-37]. Some of these reports described less symptoms of peripheral neuropathy [30,34-36], while others noted no clinically meaningful effect compared with placebo [32]. The fact that some positive results have been reported in diabetic neuropathy following ALA treatment but not in the prevention of diabetic macular edema may point to different pathomechanisms, and suggests that neuroglial damage is not an early event in diabetic macular edema formation while the breakdown of the bloodretinal barrier is the predominant causative mechanism. An improvement in insulin sensitivity in IDDM patients following the oral administration of ALA was also described [33].

The observations described in the present clinical trial on human diabetic patients stand in contrast to previously reported findings in rats $[16,17]$. However, in both animal studies, much higher ALA concentrations of 60 $\mathrm{mg} / \mathrm{kg}$ [16] and $400 \mathrm{mg} / \mathrm{kg}$ body weight were administered over a period of 30 versus 44 weeks. One may conclude that the dosage of $600 \mathrm{mg} /$ day in an adult $(7.5 \mathrm{mg} /$ $\mathrm{kg}$ body weight in an 80-kg adult) as in our study may not have been high enough to exert a permanent effect on the human retina. No upper limit for ALA intake in humans has been established yet. In contrast, safety levels have been described for animals with pronounced species-dependent differences, showing that rats appear to be far more tolerant than many other species, such as dogs $\left(\mathrm{LD}_{50}\right.$ for dogs $400-500 \mathrm{mg} / \mathrm{kg}$ [36] vs. $>2,000 \mathrm{mg} / \mathrm{kg}$ for rats [37]). Some groups reported that an oral dose of 600 mg once daily appeared to provide the optimum risk-tobenefit ratio [38]. Our daily dosage of $600 \mathrm{mg} /$ day was within the range of ALA dosages reported in the literature and could be considered safe.

One may suggest that 2 years' ALA administration was too short. In published clinical trials, the duration of oral ALA supplementation at a dose of $600 \mathrm{mg} /$ day ranged from 4 weeks [33] to 2 years (combined with an initial intravenous injection of $600 \mathrm{mg}$ for 3 days in the study by Reljanovic et al. [31]. In similar ophthalmological trials, such as the CALDIRET study [39], a follow-up of 5 years was eventually found to be too long because the final result was predictable already after 2 years.

One may criticize that imaging techniques, such as OCT, were not part of the protocol of this trial. This is due to the fact that OCT was not available at all study centers, especially in Eastern Europe. However, according to the ETDRS protocol, the gold standard for the first detection of macular edema is stereoscopic photography, as done in this trial.

In summary, antioxidants such as ALA have become popular in different medical fields. While a positive effect in the treatment of diabetic patients using the dosage of $600 \mathrm{mg} /$ day appears to be beneficial for neuropathy, no protective effect regarding the development of macular edema, another microvascular complication in diabetes, was seen in high-risk IDDM patients using the same dosage. Therefore, regular ophthalmological surveillance and interdisciplinary cooperation remain mandatory.

\section{Acknowledgements}

We thank Theresia Ring, MD, Sarah Gekeler, MD, Kathrin Hartmann, MD and Siegfried Priglinger, MD for their work in the reading centers.

\section{Disclosure Statement}

Sponsor: Bausch \& Lomb, Berlin, Germany. 


\section{Appendix 1}

Centers and principal investigators participating in the clinical trial ( 28 centers in 5 countries)

Country Center and principal investigator

Germany Eye Disease Clinic, Greifswald (Principal Investigator: Prof. Stefan Clemens).

University Eye Clinic, Leipzig (Principal Investigator: Prof. Sebastian Wolf).

Poland Medical Academy I Ophthalmology Department, Lublin (Principal Investigator: Prof. Zbigniew Zagórski).

Medical Academy, Ophthalmology Department \& Clinic, I Physician's Faculty, Warsaw

(Principal Investigator: Prof. Tadeusz Kęcik).

Ophthalmology Office, Katowice (Principal Investigator: Dr. Henryk Kozioł).

Provincial Hospital Podkarpacki Named Jana Pawła II, Ophthalmology Department, Krosno

(Principal Investigator: Dr. Antoni Bąk).

Ophthalmology Department \& Clinic by Silesian Medical Academy in Katowice, Bytom

(Principal Investigator: Prof. Stefan Pojda).

Ophthalmology Office Krzysztof Dzięgielewski s.c., Łódź (Principal Investigator: Prof. Jerzy Nawrocki).

Ukraine Medical Academy of Postgraduate Education, Department of Ophthalmology, Eye Microsurgery Center, Kyiv

(Principal Investigator: Prof. Nikolaj M. Sergienko).

Filatov Institute of Eye Diseases and Tissue Therapy of Academy of Medical Sciences of Ukraine, Odessa

(Principal Investigator: Prof. Natalia Pasechnikova).

Romania Opticontact and Occulus Center, Bucharest (Principal Investigator: Dr. Ozana Manuela Cernica).

Ophthalmologic private practice, Brasov (Principal Investigator: Dr. Stefan Sisak).

Clinical County Hospital No. 1 - Ophthalmology, Timisoara

(Principal Investigator: Dr. Valerica Augustin Ivanescu).

Central Military Hospital, Bucharest (Principal Investigator: Prof. Benone Cârstocea).

Diabetics and Nutrition Diseases Institute, Bucharest (Principal Investigator: Dr. Simona Barsan).

University Clinic Hospital Sfantul Spiridon, Clinic of Ophthalmology, Iasi

(Principal Investigator: Prof. Dr. Dorin Chiselita).

Cluj County Hospital, Cluj (Principal Investigator: Prof. Dr. Mihai Calugaru).

Russia Endocrinological Scientific Center, Moscow (Principal Investigator: Prof. Marina Shestakova).

Chair of Endocrinology and Diabetology of the Russian State University, City Clinical Hospital No. 1, Moscow

(Principal Investigator: Prof. Irina Demidova).

City Multi Field Hospital No. 2, Endocrinology Department, St. Petersburg

(Principal Investigator: Dr. Alsou Zalevskaya).

Chair of Endocrinology of Novosibirsk Medical Academy, District Clinical Hospital, Novosibirsk

(Principal Investigator: Prof. Irina Bondar).

Chair of Endocrinology and Diabetology of the Russian Medical Academy for Advanced Medical Studies,

Railway Clinical Hospital, Moscow (Principal Investigator: Prof. Alexandre Ametov).

Chair of Ophthalmology of the Russian State Medical University, City Clinical Hospital No. 15, Moscow

(Principal Investigator: Prof. Eugeniy Egorov).

Chair of Endocrinology and Diabetology of EPGE Setchenov MMA, City Clinical Hospital No. 67, Moscow

(Principal Investigator: Prof. Mihail Balabolkin).

Study centers of the RETIPON Study distributed into Western and Eastern European centers. 


\section{References}

1 Harris MI: Diabetes in America: epidemiology and scope of the problem. Diabetes Care 1998;21(suppl 3):C11-C14.

2 The Diabetes Control and Complications Trial/Epidemiology of Diabetes Interventions and Complications Research Group. Retinopathy and nephropathy in patients with type 1 diabetes four years after a trial of intensive insulin therapy. N Engl J Med 2000; 342:381-389.

3 Klein R, Klein BEK, Moss SE: Prevalence of diabetes mellitus in southern Wisconsin. Am J Epidemiol 1984;119:54-61.

4 Joussen AM, Poulaki V, Le ML, Koizumi K, Esser C, Janicki H, Schraermeyer U, Kociok N, Fauser S, Kirchhof B, Kern TS, Adamis AP: A central role for inflammation in the pathogenesis of diabetic retinopathy. FASEB J 2004;18:1450-1452.

5 Brownlee M: Glycation and diabetic complications. Diabetes 1994;43:836-841.

6 Frank RN: On the pathogenesis of diabetic retinopathy. Ophthalmology 1984;91:626634.

7 Vinores SA, Van Niel E, Swerdloff JL, Campochiaro PA: Electron microscopic immunocytochemical evidence for the mechanism of blood-retinal barrier breakdown in galactosemic rats and its association with aldose reductase expression and inhibition. Exp Eye Res 1993;57:723-735.

8 Adamis AP, Miller JW, Bernal MT, D’Amico DJ, Folkman J, Yeo TK, Yeo KT: Increased vascular endothelial growth factor levels in the vitreous of eyes with proliferative diabetic retinopathy. Am J Ophthalmol 1994;118: 445-450.

9 Bhagat N, Grigorian RA, Tutela A, Zarbin MA: Diabetic macular edema: pathogenesis and treatment. Surv Ophthalmol 2009;54: $1-32$.

10 Ishida S, Usui T, Yamashiro K, et al: VEGF164 is proinflammatory in the diabetic retina. Invest Ophthalmol Vis Sci 2003;44:21552162.

11 Du X, Matsumura T, Edelstein D, et al: Inhibition of GAPDH activity by poly (ADP-ribose) polymerase activates three major pathways of hyperglycemic damage in endothelial cells. J Clin Invest 2003;112:10491057.

12 Brownlee M: Biochemistry and molecular cell biology of diabetic complications. Nature 2001;414:813-820.

13 Heart Outcomes Prevention Evaluation Study Investigators. Effects of ramipril on cardiovascular and microvascular outcomes in people with diabetes mellitus: results of the HOPE study and MICRO-HOPE substudy. Lancet 2000;355:253-259.

14 Mayer-Davis EJ, Bell RA, Reboussin BA, Rushing J, Marshall JA, Hamman RF: Antioxidant nutrient intake and diabetic retinopathy: the San Luis Valley Diabetes Study. Ophthalmology 1998;105:2264-2270.
15 Hammes HP, Bartmann A, Engel L, Wülfroth P: Antioxidant treatment of experimental diabetic retinopathy with nicanartine. Diabetologia 1997;40:629-634.

16 Lin J, Bierhaus A, Bugert P, et al: Effect of $\mathrm{R}$-(+)- $\alpha$-lipoic acid on experimental diabetic retinopathy. Diabetologia 2006;49:10891096.

17 Kowluru RA, Odenbach S: Effect of longterm administration of alpha-lipoic acid on retinal capillary cell death and the development of retinopathy in diabetic rats. Diabetes 2004;53:3233-3238.

18 Biewenga G, Haenen GRM, Bast A: The pharmacology of the antioxidants lipoic acid. Gen Pharmac 1997;29:315-331.

19 Jacob S, Henriksen EJ, Schiemann AL, et al: Enhancement of glucose disposal in patients with type 2 diabetes by alpha-lipoic acid. Drug Res 1995;45:872-874.

20 Paasche G, Huster D, Reichenbach A: The glutathione content of retinal Müller (glial) cells: the effects of aging and of application of free-radical-scavengers. Ophthalmic Res 1998;30:351-360.

21 Packer L, Witt EH, Tritschler HJ: Alphalipoic acid as a biological antioxidant. Free Radic Biol Med1995;19:227-250.

22 Packer L, Tritschler HJ, Wessel K: Neuroprotection by the metabolic antioxidant alphalipoic acid. Free Radic Biol Med 1997;22:359378.

23 Ziegler D, Hanefeld M, Ruhnau KJ, Meissner HP, Lobisch M: Treatment of symptomatic diabetic peripheral neuropathy with the anti-oxidant $\alpha$-lipoic acid (ALADIN Study). Diabetologia 1995;38:1425-1433.

24 Ziegler D, Greis FA: $\alpha$-Lipoic acid in the treatment of diabetic peripheral and cardiac autonomic neuropathy. Diabetes 1997;46 (suppl 2):62-66.

25 Early Treatment Diabetic Retinopathy Study Research Group. Grading diabetic retinopathy from stereoscopic colour fundus photographs - an extension of the modified Arlie House Classification. EDTRS Rep No 10 Ophthalmology 1991;98:786-806.

26 Early Treatment Diabetic Retinopathy Study Research Group. Classification of diabetic retinopathy from fluorescein angiograms. EDTRS Rep No 11. Ophthalmology 1991;98: 807-822.

27 Kowurlu RA, Tang J, Kern TS: Abnormalities of retinal metabolism in diabetes and experimental galactosemia. VII. Effect of longterm administration of antioxidants on the development of retinopathy. Diabetes 2001; 50:1938-1942.
28 Gaede P, Veldel P, Parving HH, Pedersen O: Intensified multifactorial intervention in patients with type 2 diabetes mellitus and microalbuminuria: the Steno Type 2 Randomised Study. Lancet 1999;353:617-622.

29 Klein R, Moss SE, Klein BE, Davis MD, DeMets DL: The Wisconsin epidemiologic study of diabetic retinopathy. XI. The incidence of macular edema. Ophthalmology 1989;96:1501-1510.

30 Ziegler D, Hanefeld M, Ruhnau KJ, Meissner HP, Lobisch M, Schutte K, Gries FA: Treatment of symptomatic diabetic peripheral neuropathy with the anti-oxidant alpha-lipoic acid. A 3-week multicentre randomized controlled trial (ALADIN Study). Diabetologia 1995;38:1425-1433

31 Reljanovic M, Reichel G, Rett K, et al: Treatment of diabetic polyneuropathy with the antioxidant thioctic acid (alpha-lipoic acid): a two year multicenter randomized doubleblind placebo-controlled trial (ALADIN II). Alpha lipoic acid in diabetic neuropathy. Free Radic Res 1999;31:171-179.

32 Ziegler D, Hanefeld M, Ruhnau KJ, et al: Treatment of symptomatic diabetic polyneuropathy with the antioxidant alpha-lipoic acid: a 7-month multicenter randomized controlled trial (ALADIN III study). ALADIN III Study Group. Alpha-lipoic acid in diabetic neuropathy. Diabetes Care 1999;22: 1296-1301.

33 Jacob S, Ruus P, Hermann R, et al: Oral administration of RAC-alpha-lipoic acid modulates insulin sensitivity in patients with type-2 diabetes mellitus: a placebo-controlled pilot trial. Free Radic Biol Med 1999; 27:309-314.

34 Ruhnau KJ, Meissner HP, Finn JR, et al: Effects of 3-week oral treatment with the antioxidant thioctic acid (alpha-lipoic acid) in symptomatic diabetic polyneuropathy. Diabet Med 1999;16:1040-1043.

35 Ametov AS, Barinov A, Dyck PI, et al: The sensory symptoms of diabetic polyneuropathy are improved with alpha-lipoic acid: the SYDNEY trial. Diabetes Care 2003;26:770-776.

36 Packer L, Witt EH, Tritschler HJ: Alpha-lipoic acid as a biological antioxidant. Free Radic Biol Med 1995;19:227-250.

37 Cremer DR, Rabeler R, Roberts A, Lynch B: Safety evaluation of alpha-lipoic acid (ALA). Regul Toxicol Pharmacol 2006;46:29-41.

38 Ziegler D, Ametov A, Barinov A, et al: Oral treatment with alpha-lipoic acid improves symptomatic diabetic polyneuropathy: the SYDNEY 2 trial. Diabetes Care 2006;29: 2365-2370.

39 Haritoglou C, Gerss J, Sauerland C, Kampik A, Ulbig MW, CALDIRET Study Group: Effect of calcium dobesilate on occurrence of diabetic macular oedema (CALDIRET study): randomised, double-blind, placebo-controlled, multicentre trial. Lancet 2009;373: 1364-1371. 